\title{
RABIA EN UN GATO DOMÉSTICO (Felis silvestris catus) EN EL MUNICIPIO DE YUMBO, VALLE DEL CAUCA, COLOMBIA
}

\section{FELINE RABIES IN A DOMESTIC CAT (Felis silvestris catus), YUMBO, VALLE DEL CAUCA, COLOMBIA}

\author{
Fernando Favian Castro Castro ${ }^{1}$, Maria Patricia Mateus Rodríguez ${ }^{2}$.
}

\begin{abstract}
${ }^{1}$ M.V. Ph.D., Profesional Independiente, Rúa Pedro Delmanto 939 Botucatu Sao Paulo Brasil, e-mail: fernandomorcegos@ gmail.com; ${ }^{2}$ T.R. Especialista Administración en Salud, Profesional Independiente, carrera 10 No. 131 a-92, casa 32, Bogotá, Colombia, e-mail: mmateusrodriguez@hotmail.com
\end{abstract}

Rev. U.D.C.A Act. \& Div. Cient. 19(1): 243-246, Enero-Junio 2016

\section{INTRODUCCIÓN}

La rabia es una enfermedad mortal que ataca a todas las especies de sangre caliente, incluido el hombre, producida por un virus que, generalmente, se disemina por la saliva de los animales infectados. Da origen a una alteración del sistema nervioso central, causando la muerte (Brass, 1995).

De acuerdo con el comportamiento epidemiológico, se pueden identificar dos ciclos predominantes de la enfermedad: el ciclo urbano, donde el virus es trasmitido por perros y gatos y el ciclo silvestre, donde los transmisores son animales silvestres, como marsupiales, zorros, zarigüeyas, mapaches y murciélagos. En América Latina, el murciélago hematófago es el principal transmisor de la enfermedad, seguido por los cánidos domésticos y otros carnívoros, como zorros, lobos, coyotes, chacales y mapaches, implicados en el ciclo epidemiológico de la enfermedad, tanto en América del Norte como Europa y Asia (Flores, 1978; OPS, 2003; Nadin-Davis, 2007; Bofill et al. 1988).

El agente que produce la enfermedad es un virus que pertenece a la Familia Rabdoviridae género Lysavirus, cuya forma es de bala. Se destruye fácilmente con los agentes físicos más conocidos, como el calor y la luz de los rayos ultravioleta, que tienen acción anti microbiana y agentes químicos, como la cal, la lejía, detergentes, como jabones y los halógenos, como el cloro y el yodo (Bleck, 2006).

El virus ingresa al cuerpo por pérdida de integridad de la piel o por aerosoles, busca un nervio periférico trasladándose a la médula espinal y de allí al cerebro. Posteriormente, se disemina a todos los órganos del cuerpo, incluso las glándulas salivares, donde se elimina constantemente (Brass, 1995). Existen varios métodos de transmisión: uno de las principales es por la saliva, que se propaga a las víctimas, como es el caso de la rabia silvestre, que ocurre por mordeduras de zorros, de murciélagos y de ardillas; por medio de aerosoles procedentes de saliva, de orina y de materia fecal de animales infectados, al ingresar sin protección a refugios, como cuevas, árboles huecos y casas abandonadas (Dietzschold et al. 2008); a través de contacto y manipulación sin protección adecuada de animales enfermos, que eliminan virus (Best et al. 2004) que, según Brass (1995), está en la saliva dos días antes de presentar sintomatología nerviosa evidente.

El periodo de incubación: Es el tiempo desde que el organismo es expuesto al virus hasta que manifiesta los primeros síntomas. Este tiempo es variable y presenta, dentro de la misma especie, fluctuaciones, a veces muy grandes, que tienen que ver, principalmente, con el sitio de inoculación (mayor periodo de incubación, mientras más lejos del cerebro quede el sitio de entrada del virus), la cantidad de virus que haya podido inocular y la vía por la que logró ingresar (Brass, 1995). En los bovinos, se presenta entre 25 y 150 días, de acuerdo al sitio de ingreso del agente (ICA, 2008); en equinos es más corto, de 20 a 85 días; en ovinos y caprinos es de 20 a 65 días y en gatos, de 9 días hasta un año, generalmente, en la mayoría de casos, aparecen los síntomas 4 semanas después del contagio (Paho, 2007).

Los principales síntomas: Presenta letargia y parálisis de los músculos de la deglución, razón por la cual, se produce abundante salivación y pueden tener dificultad para beber, algunas veces se puede confundir con obstrucción de esófago, por elementos extraños. En ocasiones, se observan lagrimeo y secreción nasal, siendo el síntoma principal la parálisis progresiva del tren posterior, que lleva a la postración, coma y muerte (ICA, 2008). El periodo de tiempo desde que aparecen los síntomas evidentes hasta la muerte es de 3 a 5 días, en perros y en gatos (Minsalud, 2010). 
En el municipio de Yumbo, departamento del Valle del Cauca, en junio de 2014, se presentó un foco de rabia silvestre, en la vereda el Chocho. La zona afectada es de topografía montañosa, ubicada en la zona rural $15 \mathrm{~km}$ de la cabecera municipal, donde existen casas de descanso para fin de semana y un número reducido de explotaciones pecuarias y pequeñas especies.

El animal que enfermó era un gato doméstico (Felis silvestris catus), de raza criollo, género macho, estado lactante de 58 días de edad. Tenían dos hermanos de camada, cuya madre, con el esquema de vacuna contra la rabia completo, última inmunización día 5 noviembre del 2013, no presentó sintomatología de la enfermedad durante la observación de la cuarentena. El gato enfermo presentó síntomas nerviosos y cambios de comportamiento, manifestando ataques de furia a otros animales, como gallinas, que convivían en el predio. Posterior al ataque a gallinas, se les realizó vigilancia epidemiológica y no presentaron síntomas de la enfermedad, ya que las aves no tienen receptores específicos para el virus de la rabia. El gato atacó objetos inanimados, como escobas, palos e, incluso, agredió físicamente a personas, como fue un niño menor de doce años, mordido en la mano y su padre en la pantorrilla, quienes notificaron a las autoridades de salud el accidente rábico y encerraron al gato, que murió con sintomatología nerviosa, para luego ser recogido por las entidades de salud. Los dos hermanos del gato afectado no fueron encontrados en un rastreo realizado en la zona boscosa.

El caso fue diagnosticado como rabia, mediante la prueba de IFD inmunofluorescencia directa, en el Instituto Nacional de Salud en Bogotá Colombia, cuya variante antigénica fue la número tres. El origen del virus fue el murciélago hematófago Desmodus rotundus, se desconoce cómo se transmitió el virus del murciélago al gato; la gata acostumbraba a llevarse las crías a una zona boscosa amplia durante las noches, a 50m de distancia de la casa, una zona geográfica que tiene reportes de ataques de murciélagos hematófagos en bovinos. Las formas más frecuentes de transmisión entre vampiros son las heridas, principalmente, por mordeduras causadas al presentarse peleas entre individuos de la colonia (Villa, 1976; Gomes \& Uieda, 2004).

La rabia es una enfermedad zoonótica de carácter mortal. La letalidad de la rabia es del $100 \%$, aunque han sido registrados casos de cura en humanos, mediante coma inducido y terapia de soporte o cura espontánea, en casos de infección experimental, en modelos animales, que dejaron importantes secuelas motrices (CDC, 2011).

La rabia silvestre en felinos en Colombia se ha venido presentando frecuentemente. De acuerdo a reportes del Ministerio de Salud y Protección Social (2014), en el periodo del 2004 al 2014, se presentaron en Colombia 10 casos. En el Valle del Cauca se han manifestado cuatro casos, en los municipios El Dovio, en el 2000; Ginebra, en el 2009; Roldanillo, en el 2012 y Yumbo, en el 2014. De acuerdo a la variante antigénica, tres de los murciélagos hematófagos, han sido los transmisores, en un $75 \%$ de la casuística, en el departamento y un $25 \%$, una variante antigénica, cuatro perteneciente a una especie de murciélagos no hematófagos Tadarida brasiliensis.

La rabia en gatos ha llevado a desenlaces fatales en humanos, en Colombia, como son los casos del municipio de Santander de Quilichao, en el Departamento del Cauca, municipio de Moniquirá, en el Departamento de Boyacá y en el municipio de Roldanillo, en el Departamento del Valle, por la cercanía de estos pequeños felinos al hombre y sus hábitos alimenticios variados, que incluyen murciélagos (Fotografía 1a y b).

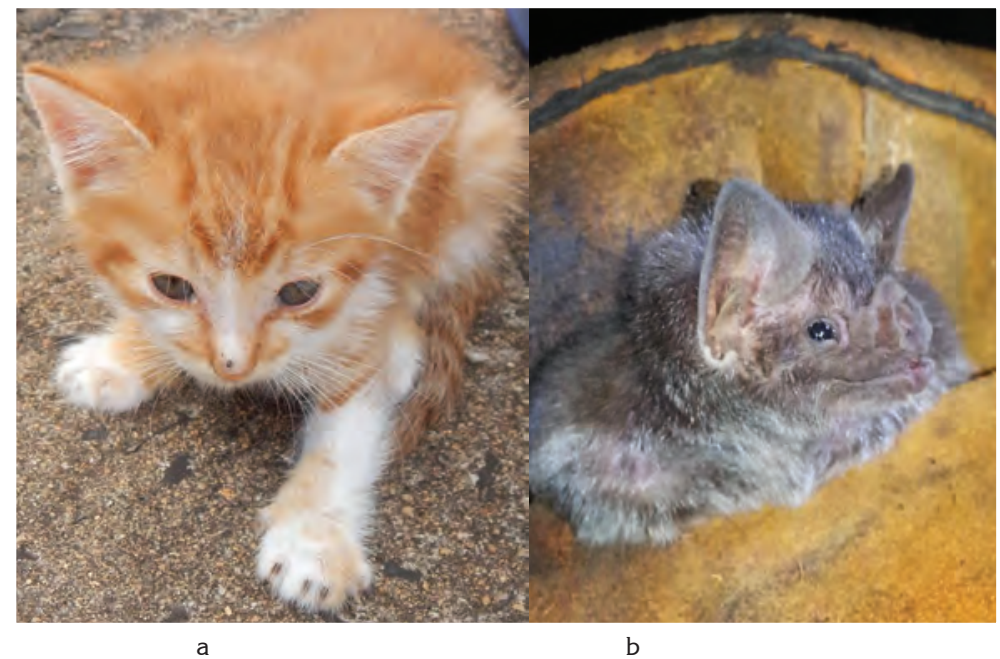

Fotografía 1. a) Gato (Felis silvestris catus); b) Murciélago hematófago Desmodus rotundus, tomado por Fernando Castro y Pablo Arboleda. Departamento del Valle del Cauca, Colombia. 


\section{MATERIALES Y MÉTODOS}

Atención de la notificación por autoridades de salud del municipio de Yumbo de las mordeduras de gato a dos habitantes, realizándose la visita al lugar para efectuar la valoración de las personas y ser remitidas al hospital local, para su tratamiento post exposición contra la rabia; observación y colecta del animal muerto, sospechoso de rabia; toma de muestras de cerebro y envío al laboratorio de diagnóstico del Instituto Nacional de Salud en Bogotá, donde se confirma rabia, con la prueba IFD inmunoflorecencia directa para rabia y, posteriormente, la variante antigénica tres de murciélago hematófago $D$. rotundus.

El comité de zoonosis departamental, liderado por la Secretaría de Salud de la gobernación del Valle del Cauca, Secretaría de Salud del Municipio de Yumbo y el Instituto Colombiano Agropecuario seccional Valle del Cauca, convocan para la atención de la situación, donde se prioriza la vacunación de los humanos expuestos, la vacunación focal y peri focal de mascotas, de bovinos y de equinos, en la zona afectada, con radio de $7 \mathrm{~km}$.

Se hace un rastreo epidemiológico en veinte predios pecuarios de la zona, visitando y revisando animales de producción. Del total de las fincas visitadas, dos predios tenían ataques esporádicos de murciélagos hematófagos. Se realizó las capturas en abrigos, donde los propietarios informan su presencia. Se utilizaron mallas de niebla, GPS, guantes de sujeción, halotano, bolsa de tela, jaulas y pinzas de sujeción.

\section{RESULTADOS Y DISCUSIÓN}

Se encontraron veinte predios pecuarios con una población de 208 bovinos, 17 equinos, 13 ovinos, dos predios con ataques ocasionales de murciélagos, donde los bovinos afectados no presentaron mordeduras frescas en el momento de la visita. Se recomendó utilizar pasta vampiricida en un futuro ataque y la vacunación inmediata, contra la rabia de los animales.
Después del rastreo epidemiológico, no se observaron casos nuevos de rabia en la zona. Las personas de la vereda denuncian la presencia de murciélagos. Se visitan los refugios y no se encuentran murciélagos hematófagos; se colectan ejemplares no hematófagos, en cuatro predios, para medir la actividad viral de la zona, incluida la escuela rural, que está ubicada a $100 \mathrm{~m}$ del foco, donde permanecen murciélagos en el local, con un total de 27 ejemplares capturados: se colectaron 22 de la subfamilia Carolliae y 5 de la subfamilia Stenodermatinae; fueron enviados al laboratorio de zoonosis del ICA en Bogotá, resultando negativos a IFD inmunofluorescencia directa para rabia (Tabla 1 ).

La forma de contagio del virus de la rabia variante antigénica tres de murciélago hematófago al gato, se pudo dar por contacto directo en la zona boscosa, donde pernoctaba el felino y su estado de indefensión.

Los gatos permanecen, en su mayoría, en estado silvestre dentro y fuera del perímetro urbano, por lo que no es fácil llevar a cabo buen control de natalidad con las campañas de esterilización y la vacunación antirrábica en esta especie, así como la realización de un censo total de la población.

Las últimas coberturas vacunales en gatos, de acuerdo al Ministerio de Salud y Protección Social muestran, del 2010 al 2013, que son del 59, 70, 76 y 65, teniendo en cuenta que no existe un censo definido para esta especie, en la mayoría de los departamentos.

Agradecimientos: Andrés Osejo Barona, Epidemiólogo ICA -Valle y Cauca-; Pablo Arboleda Simmons, Médico Veterinario ICA -Valle-; Carlos Javier López, Médico Veterinario ICA -Valle-; Ángel Tabares, Técnico ICA -Valle- y Miembros del Comité de Zoonosis Gobernación del Valle del Cauca. Conflicto de intereses: El manuscrito fue preparado y revisado con la participación de los autores, quienes declaramos que no existe conflicto de intereses que ponga en riesgo la validez de los resultados presentados.

Tabla 1. Captura de murciélagos en el municipio de Yumbo, Valle del Cauca.

\begin{tabular}{|l|l|l|l|l|l|c|}
\hline \multicolumn{1}{|c|}{ Predio } & \multicolumn{1}{|c|}{ Latitud } & \multicolumn{1}{c|}{ Longitud } & $\begin{array}{c}\text { Altitud } \\
\text { msnm }\end{array}$ & \multicolumn{1}{c|}{$\begin{array}{c}\text { Especie } \\
\text { Murciélago }\end{array}$} & $\begin{array}{c}\text { Resultado } \\
\text { Rabia }\end{array}$ & Capturas \\
\hline Germania & $3^{\circ} 37^{\prime} 56.3514 "$ & $76^{\circ} 31^{\prime} 51.24 ”$ & 1637 & $\begin{array}{l}\text { Sturnia } \\
\text { erythromos }\end{array}$ & negativo & 5 \\
\hline Escuela Chocho & $3^{\circ} 37^{\prime} 23.5914^{\prime \prime}$ & $76^{\circ} 31^{\prime} 2.9994^{\prime \prime}$ & 1616 & Carollia perspicillata & negativo & 7 \\
\hline Bodega Tolima & $3^{\circ} 37^{\prime} 29.4594^{\prime \prime}$ & $7^{\circ} 31^{\prime} 18.84^{\prime \prime}$ & 1566 & C. perspicillata & negativo & 7 \\
\hline La Marranera & $3^{\circ} 37^{\prime} 19.9914^{\prime \prime}$ & $7^{\prime} 31^{\prime} 54.12^{\prime \prime}$ & 1534 & C. perspicillata & negativo & 8 \\
\hline TOTAL & & & & & & 27 \\
\hline
\end{tabular}




\section{BIBLIOGRAFÍA}

1. BEST, M.; GRAHAM, M.L.; LEITNER, R.; OUELLETTE, M.; UGWU, K. 2004. (Eds.). Laboratory Biosafety Guidelines ( $3^{\text {rd }}$ ed). Canada: Public Health Agency of Canada. Disponible desde Internet en: http://www. phac-aspc.gc.ca/lab-bio/res/psds-ftss/rab-eng.php (con acceso 17/10/2015).

2. BLECK, T.P. 2006. Rabies. In: Guerrant, R.L.; Walker, D.H; Weller, P.F. (Eds.). Tropical Infectious Diseases: Principles, Pathogens, and Practice ( $2^{\text {nd }}$ ed.). Philadelphia, PA: Elsevier Churchill Livingston. p.839-851.

3. BRASS, D.A. 1995. Rabies in bats: natural history and public health implications. Epidemiol. Infect. 114(3):522. Disponible desde Internet en: http://www.ncbi.nlm. nih.gov/pmc/articles/PMC2271301/?page $=1 \quad$ (con acceso 16/08/2015).

4. BOFILL, P.; RAMIREZ, J.; MONTAÑEZ, A.; MARTINEZ, Q.; GONZALEZ, L.; FUSTES, E. 1988. Manual de enfermedades Infecciosas. Tomo l. La Habana: Ministerio de Educación Superior, Instituto Superior de Ciencias Agropecuarias. p.139-187.

5. CENTER FOR DISEASE CONTROL AND PREVENTION CDC-. 2011. Recovery of a patient from clinical rabies California. MMWR Morb. Mortal Wkly Rep. 2011, pp. 6155. Disponible desde Internet en: http://www.cdc.gov/ mmwr/pdf/wk/mm6104.pdf (con acceso 22/09/2015).

6. DIETZSCHOLD, B.; LI, J.; FABER, M.; SCHNELL, M. 2008. Concepts in the pathogenesis of rabies. Futur. Virol. 3(5):481-490.

7. FLORES, C.R. 1978. La rabia, los murciélagos y el control de los hematófagos. Ciencia Veterinaria. 2:67. Disponible desde Internet en: http://www.fmvz.unam. $\mathrm{mx} / \mathrm{fmvz} /$ cienciavet/revistas/CVvol2/CVv2c2.pdf (con acceso 10/04/2015).

8. GOMES, M.N.; UIEDA, W. 2004. Abrigos diurnos, composição de colônias, dimorfismo sexual e reprodução do morcego hematófago Desmodus rotundus (E. Geoffroy) (Chiroptera, Phyllostomidae) no Estado de São Paulo, Brasil. Rev. Bras. Zoologia 21(3):629-638.
9. INSTITUTO COLOMBIANO AGROPECUARIO -ICA-. 2008. Rabia silvestre: grave y mortal enfermedad. $1^{\text {a }}$. Ed. Bogotá: Produmedios. 32p.

10. MINISTERIO DE SALUD Y PROTECCIÓN SOCIAL. 2014. Colombia completa siete años sin casos de rabia humana transmitida por perro. Disponible desde Internet en: http://www.minsalud.gov.co/Paginas/ Colombia-completa-siete-a\%C3\%B1os-sin-casos-de-rabia-humana-transmitida-por-perro.aspx (con acceso 14/07/2015).

11. MINISTERIO DE SALUD Y PROTECCIÓN SOCIAL. 2010. Protocolo de vigilancia de rabia, Instituto Nacional de Salud. Disponible desde Internet en: http://www.minsalud.gov.co/Documentos\%20y\%20 Publicaciones/Protocolo\%20Rabia.pdf (con acceso 14/010/2015).

12. NADIN-DAVIS, S.A. 2007. Molecular epidemiology. In: Jackson, A.C.; Wunner, W.H. (eds). Rabies. $2^{\text {nd }}$ ed. San Diego: Elsevier. p.69-122.

13. ORGANIZACIÓN PANAMERICANA DE LA SALUD -OPS. 2003. Zoonosis y enfermedades transmisibles comunes al hombre y a los animales. Vol Il, Clamidias, Rickettsiosis y Virosis. $3^{\mathrm{a}}$. Ed. Washington D. C: OPS. 3 vol. Publicación Científica y Técnica No. 580. Disponible desde Internet en: http://iris.paho.org/xmlui/ bitstream/handle/123456789/710/9275319928. pdf?sequence $=2$ (con acceso 20/07/2015).

14. PAHO. 2007. Manual de normas y procedimientos para la vigilancia, prevención y el control de la rabia silvestre. Buenos Aires. Disponible desde Internet en: http://www.paho.org/arg/publicaciones/publicaciones\%20virtuales/cdmanualRabia/medidascontrolanimalagresor.html (con acceso 15/09/2015).

15. VILLA R., B. 1976. Biología de los murciélagos hematófagos. Instituto de Biología UNAM. México. p.94-99. Disponible desde Internet en: http://www.fmvz.unam. $\mathrm{mx} / \mathrm{fmvz} /$ cienciavet/revistas/CVvol1/CV1v1c04.pdf (con acceso 15/07/2015).

Recibido: Agosto 20 de 2015

Aceptado: Enero 6 de 2016

Cómo citar:

Castro Castro, F.F.; Mateus Rodríguez, M.P. 2016. Rabia en un gato doméstico (Felis silvestris catus) en el municipio de Yumbo, Valle del Cauca, Colombia. Rev. U.D.C.A Act. \& Div. Cient. 19(1): 243-246. 